\title{
Seasonal variability of interception and water wetta- bility of common oak leaves
}

\author{
A. Klamerus-Iwan, E. Błońska
}

Klamerus-Iwan A., Błońska E., 2017. Seasonal variability of interception and water wettability of common oak leaves. Ann. For. Res. 60(1): 63-73.

Abstract. Wettability of leaves and the resulting amount of interception loss of tree crowns is an important component of the atmosphere-tree stand-soil system balance. In the study, we hypothesized that changes occurring in leaves during the vegetation period can significantly affect the amount of rainwater retained by plants and wettability of leaves which is expressed by the contact angle between drops and leaves. We evaluated the hypothesis based on measurement series, which combined direct spraying of leaves with water at different stages of development at a constant temperature with observations made with an electron scanner which was used to determine changes occurring within a leaf, while the photographic method was used to analyze the contact angle of drops. The study involved common oak (Quercus robur). Samples of twigs derived from this species were collected in the area of Przedbórz (Poland) forest district, in particular from the trees with well-developed crowns. Twigs were collected from 10 trees of similar age (35-40 years). The resulting database contained experimental data on changes of raindrop adhesion on oak leaves throughout the growing season. The internal contact angle of drops was within the range of $150^{\circ}$ on the upper side of the leaf and $160^{\circ}$ on the underside in May, up to $15^{\circ}$ and $35^{\circ}$ in November on the upper and underside of the leaves. Loss of interception was established at $6 \%$ at the beginning of the growing season up to $22 \%$ in autumn. It was concluded that the wettability and the level of interception increases in line with the age of a leaf. Keywords hydrophilicity, cuticle waxes, SEM, PCA, ecohydrology, Poland

Authors. Anna Klamerus-Iwan (a.klamerus-iwan@ur.krakow.pl) - University of Agriculture in Kraków, Faculty of Forestry, Department of Forest Engeenering, Al. 29 Listopada 46,31-425 Kraków, Poland; Ewa Błońska - University of Agriculture in Krakow, Faculty of Forestry, Department of Forest Soil, Al. 29 Listopada 46, 31-425 Kraków, Poland.

Manuscript received August 16, 2016; revised November 21, 2016; accepted December 6, 2016; online first December 20, 2016. 


\section{Introduction}

The process of interception plays a very important role in the hydrologic balance (Aussenag 2000). In numerical terms, interception is a major component of hydrologic balance. Pike \& Scherer (2003) even suggested that it is a key problem of forest hydrology. Calder (1999) and then Chen et al. (2013) suggested the possibility of retaining about $10-50 \%$ of the total precipitation on the surface of leaves. When assessing the interception, it is necessary to consider the impact of factors related to both, misted surface (Tranqada \& Erb 2014, Rosado \& Holder 2013, Fernandez \& Eicherd 2009) and the characteristics of the precipitation (Nanko et al. 2006, Klamerus-Iwan 2014a). Gash et al. (1995), Klaassen et al. (1998), Liu (1997), Chang (2006) determined the retention possibility of crowns of deciduous and coniferous trees within $0.5-8.2 \mathrm{~mm}$. In this context, it can be mentioned (Keim 2004) that the ability of crown to retain water can be treated as a constant value only for a single precipitation, subsequent precipitation can modulate this ability. With regard to numerous factors affecting the interception, it is necessary to evaluate precisely, whether basic processes and both physical and chemical changes, occurring during the vegetation period, can affect interception (Xiao and McPherson 2016). Seasonal and species variations were observed by Neinhuis \& Barthlott (1997), Nanko et al. (2013), Holder (2007), Koch \& Bartholott (2009). According to Owsiak et al. (2013) it can be associated with seasonal changes of precipitable water temperature. Leaves are plant organ, in which changes in the composition of the epicuticular wax occur during development. These differences can be explained by phenological changes and re-metabolism of the components produced at initial stages of the development (Kozlowski \& Pallardy 1979). Differences in the chemistry of the wax layer are observed in abaxial and subaxial surfaces of leaves. There is a system which divides the plants into the most hydrophilic and superhydrophilic (Aryal \& Neuner 2010). Koch \& Barthloot (2009) as well as Otten \& Herminghaus (2004) associate wetting efficiency with hairs covering leaves' surface of several species.

With no doubt, the amount of wax in the cuticle has a big impact on the amount of retained water and the tilted angle between drops and leaf (Extrand 2005, Li and Amirfaz 2008). Seasonal changes in the composition of the epicuticular wax of oaks were presented by Gulz \& Muller (1992). Along with age of leaves, they observed an increase in the amount of hydrocarbons and decrease in the amount of aldehydes and fatty acids. The values reported in May for e.g. wax esters and fatty acids are much higher compared to other months of the vegetative season.

The effect of exceptional hydrophobicity of lotus leaf (Ensikat et al. 2010, Barthlott 1997) as well as their self-cleaning (Bhushan et al. 2010) seem to be comprehensively tested.

Superhydrophobicity provides protection against plant pathogens such as fungi and bacteria as the infection is inhibited by the lack of water and humidity (Stosch et al. 2007), which is very important in terms of oaks.

The objective of this study is to assess the seasonal changes of tilted angles between drops and leaves and simultaneously, the amount of water which can be retained in the crown of trees. Common oak (Quercus robur) was selected for the study as it is a species occurring in large numbers and exerting an economic impact across Europe (Pretzsch et al. 2013). An additional objective was to investigate the differences in the degree of adhesion of water between the upper and lower surface of leaves.

In the study, we hypothesized that changes occurring in leaves during the vegetation period can significantly affect the amount of rainwater retained by plants and wettability of leaves which is expressed by the contact angle between drops and leaves.

We evaluated the hypothesis based on meas- 
urement series associated direct spraying of leaves with water at different stages of development at a constant temperature. Additionally, scanning electron was used to determine changes occurring within a leaf, while the photographic method was used to analyze the contact angle of drops.

The combination of physiology and forest hydrology seems to be necessary and justified. Presented studies demonstrate that change in adhesion and hydrophilicity of leaves must be taken into account when studying the rainfall interception of trees. Precise determination of seasonal changes can cause a significant difference in hydrologic balance in forests.

The studies presented fulfill the missing element between sesonal changes and ecohydrological properties of amount of water that can be retained in the crowns or interception losses in the water balance of the ecosystem. This is an important problem not only from the viewpoint of ecophysiology and hydrology (Limm et al. 2009, Johnstone \& Dawson 2010, Adamec 2013, Berry et al. 2014).

\section{Methods}

\section{Sample collection}

Leaves of common oak (Quercus robur L.) were analyzed. Samples were collected within Przedbórz area, which belongs to ecological class "0," therefore without the influence of impurities and which is free from damages and contaminations. The area is located in the central part of Poland, with average monthly air temperature of $7.4^{\circ} \mathrm{C}$ and average monthly precipitation totals of $649 \mathrm{~mm}$. We selected 10 trees for the study with a normally-developed crown. The twigs were collected from 8 areas of the crown (from 2 heights and 4 geographical directions) to avoid the influence of external factors affecting the properties and thickness of the wax covering the leaves. The entire experiment was repeated between 15 and 20 day of each month from April to November 2015. For the studies aimed at wettability and to produce images using Scanning Electron Microscope (SEM), individual leaves were used. Studies on interception simulating precipitation at a fixed dose was carried out using twigs of about $30-35 \mathrm{~cm}$ selected from different locations and within larger twigs transported to the laboratory. The experiment was conducted immediately after transporting to the laboratory. All analyzes were performed in the laboratory under constant, controlled temperature conditions, humidity, and eliminating the effect of wind, air pressure or humidity. Earlier studies indicate that the effect of temperature is important in terms of water density and adhesion of drops to the leaves (Owsiak et al. 2013).

\section{Evaluation of morphology}

Samples for electron microscopy analysis were collected from selected leaves. The JEOL JSM5410 scanning electron microscope was used in the experiment. Fragments of the leaves were dried, fixed and then sprayed with gold. For such prepared samples, a series of images were produced at different zoom range. We were interested in the construction of cuticle, which is a thin layer covering the external wall of epidermal cells.

To carry out a more complete analysis of the results, we used the studies conducted by Gülz \& Müller (1992) wherein the composition of epicuticular wax lipids of Quercus robur during a 1-year vegetation period (Table 1) was presented.

\section{Classification of wettability}

Each month, above the leaves, from a sprinkler, water was condensed from a nozzle of a diameter equal to $0.45 \mathrm{~mm}$.

Condensation was proceeded until 30 images of drops were collected for further analysis of tilted angle between drops and leaf surface 
on the axial and abaxial site. The images were produced in a shadow-free chamber. To complete image documentation, Canon Eos 450D camera with EF $100 \mathrm{~mm} \mathrm{f} / 2.8$ Macro USM lens, was used. Internal contact angle between a drop and a leaf was considered (Figure 1). Measurements of the contact angle of drops $(\alpha)$ were performed using Sigma Scanv5 program. The scheme is presented in Figure 1.

Measurements were conducted following the example described by Owsiak et al. (2013) when measuring the effect of temperature on the size and tilted angle of drops. Methodology and terminology used to describe the parameters of the drops' contact with the surface, is in agreement with the commonly used one (Nanco et al. 2013, Rosado \& Holder 2013). The obtained values of contact angles between drops and leaves were compared with classification proposed by Aryal \& Neuner (2010) (Table 1).

\section{Interception measurements}

Determination of wettability understood as the degree of adhesion of drops, was supplemented with interception determination for individ-

Table 1 Ranking grades of hydrophobicity based on the contact angle of water drops (Aryal \& Neuner 2010)

\begin{tabular}{ll}
\hline Contact angle $\left[{ }^{\circ}\right]$ & Classification \\
\hline$<40$ & Superhydrophilic \\
$40-90$ & Highly wettable \\
$90-110$ & Wettable \\
$110-130$ & Non-wettable \\
$130-150$ & Highly non-wettable \\
$>150$ & Superhydrophobic \\
\hline
\end{tabular}

ual twigs. Quantitative abilities to retain water were experimentally determined from the simulated precipitation. The collected twigs were weighed, and further subjected to simulation with a stable dose of precipitation followed by re-weighting under wet condition. Setting the twigs during spraying was similar to their natural orientation on the tree. A fixed dose of water $(P)$ equal to $5.0 \mathrm{~g}$ was established. The twigs were sprayed with water from established distance at the temperature of $21^{\circ} \mathrm{C}$, that is by 1 degree lower compared to that from the laboratory. Thus, conditions observed in the field were simulated (Woś 1996).

\section{Statistical analysis}

In order to reduce the number of variables in the statistical data set and visualize the multivariate data set as a set of coordinates in a high-dimensional data space, the Principal Component Analysis (PCA) was used. The PCA method was also used in order to interpret other factors, depending on the type of data set. In PCA analysis, interception of twigs and wettability, were used. For a more comprehensive analysis of the results, physiological data on the composition of epicuticular wax lipids of Quercus robur during a 1-year vegetation period were used from the literature (Gülz \& Müller 1992) (Table 2) because the objective of this study was the analysis of hydrological consequences of these changes.

General linear model (GLM) was used to establish the relationship between the angles of drops on the leaves and between the properties of leaves' surface and interception. Differences between mean values were evaluated using the nonparametric Kruskal-Wallis test. The statis-

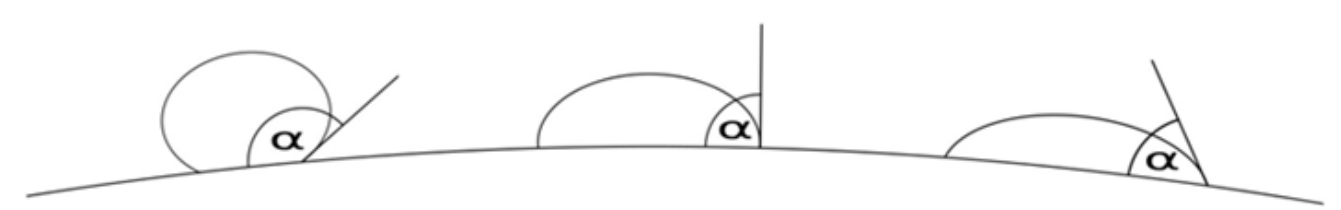

Figure 1 Scheme of contact angles $(\alpha)$ between a drop and a leaf at different stages of the vegetative season 66 
tical significance of the results was tested at the significance level of $\alpha=0.05$. All statistical analyzes were performed with Statistica 10 software (2010).

\section{Results}

\section{Evaluation of morphology}

The resulting images produced with electron microscopy indicate changes in the construction of layer of oak leaves. These changes

Table 2 The composition of epicular wax lipids of Quercus robur during a 1 year vegetation period (Gülz \& Müller 1992)

\begin{tabular}{lcccccc}
\hline & Hydrocarbons & Wax esters & Aldehydes & Alcohols & Fatty acids & Triterpentols \\
\hline May 6 & $6.9+/-0.7$ & $19.1+/-5.2$ & & $44.0+/-15.0$ & $243+/-8.5$ & $1.4+/-0.3$ \\
May 6 & $2.4+/-0.3$ & $7.2+/-1.4$ & $8.8+/-3.0$ & $70.5+/-1.7$ & $9.5+/-2.5$ & $0.4+/-0.3$ \\
June & $2.0+/-0.5$ & $3.2+/-0.9$ & $27.8+/-7.2$ & $50.6+/-8.3$ & $13.2+/-2.6$ & $3.3+/-2.5$ \\
July & $2.9+/-0.6$ & $2.5+/-0.2$ & $23.0+/-1.6$ & $36.3+/-2.6$ & $24.5+/-3.2$ & $7.4+/-0.8$ \\
August & $3.3+/-1.0$ & $3.2+/-1.2$ & $22.7+/-0.6$ & $38.2+/-0.5$ & $23.2+/-2.4$ & $8.5+/-0.9$ \\
September & $4.5+/-0.3$ & $3.2+/-0.6$ & $21.8+/-0.5$ & $37.5+/-2.8$ & $18.7+/-1.8$ & $8.1+/-1.0$ \\
October & $4.4+/-0.3$ & $7.7+/-2.1$ & $13.6+/-1.9$ & $41.3+/-4.0$ & $18.3+/-1.8$ & $9.6+/-0.8$ \\
November & $5.2+/-0.2$ & $7.1+/-0.3$ & $12.9+/-1.4$ & $44.9+/-1.9$ & $16.0+/-1.8$ & $8.4+/-1.2$ \\
\hline
\end{tabular}
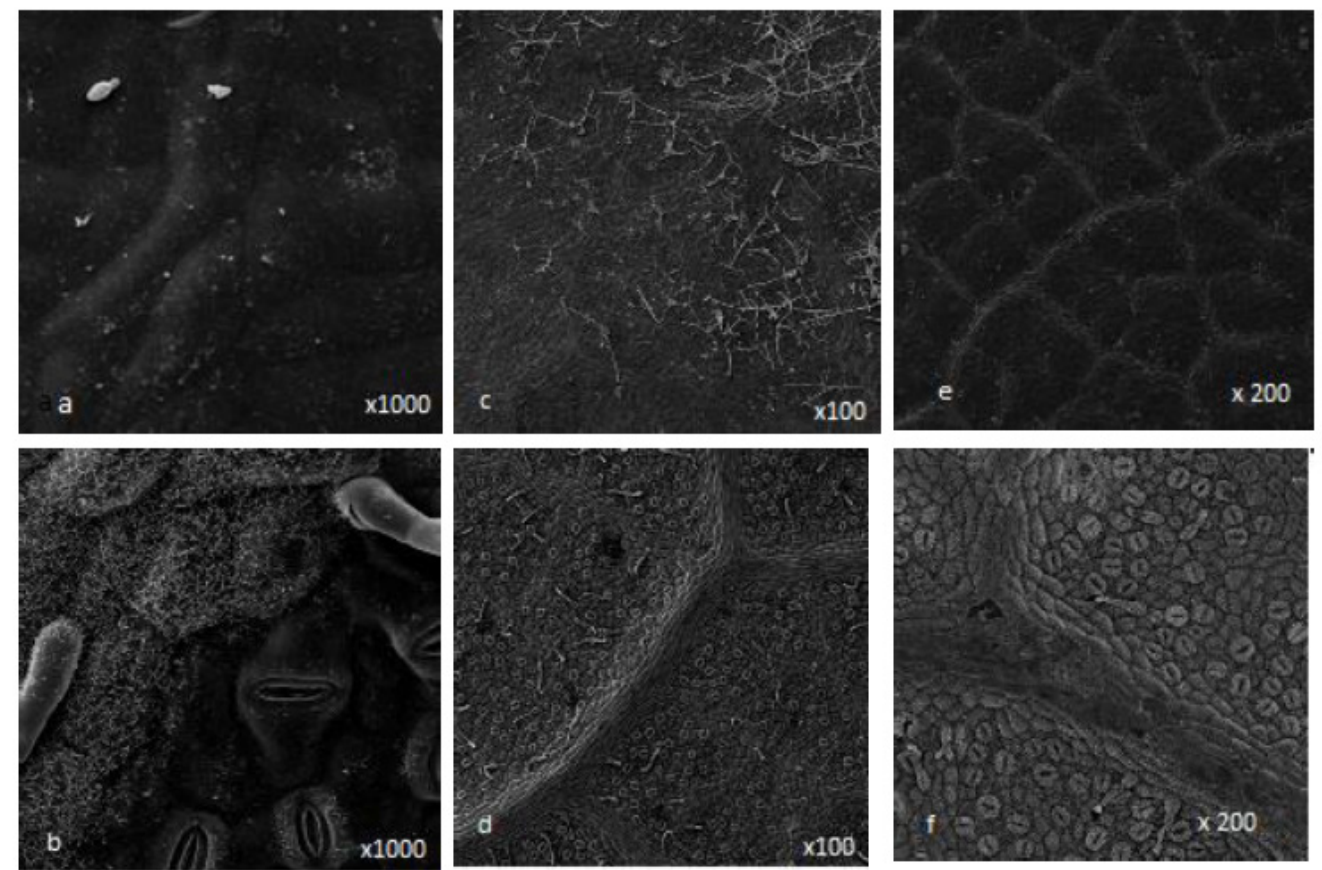

Figure 2 SEM micrographs of adaxial and abaxial oak leafe surfaces duron vegetation season. Abbrev.: a the upper side of the oak leaf in May (x1000); $\mathrm{b}$ - the lower side of the leaf oak in May (x1000); c- upper side of the oak leaf in July (x100); $\mathrm{d}$ - the lower side of the oak leaf in July (x100); e - the upper side of the oak leaf in October (x200); $\mathrm{f}$ - the lower side of the oak leaf in October (x200) 
relate both, the upper side and underside of the leaves. Figure 2 presents selected images with seasonal changes of cuticle. In the picture denoted with 'a' letter, wax crystals can be clearly observed. In this form it appears at the beginning of the vegetation period. Pictures c and $\mathrm{d}$ demonstrate the upper side and underside of a leaf in July. Thanks to lower magnification, we managed to present a larger surface. Wax crystals responsible for hydrophobicity of leaves are no longer so clear. In the pictures taken in October (Fig. 2 e, f), we can observe the lack of such forms on the outer layer of cuticle or their presence in the form eroded by atmospheric factors.

\section{Degree of wettability and interception}

Contact angle is a physical concept associated with the state of the surface of the leaves. By obtaining values defining angles adhesion drops into the leaf, we can infer the degree of wettability. Wettability is closely related to the amount of water that can be retained on the surface and thus the retention properties of the crown. Figure 3 and 4 demonstrate seasonal changes between the contact angles of drops and the surface of leaves. Figure 3 shows the upper side of a leaf. Much lower values can be observed in the first month in which the analyzes were performed. The values obtained in April are statistically different from those reported within the next 3 months. The data obtained between the tilted angles of drops and the leaf surface were compared with classification proposed by Aryal \& Neuner (2010) (Table 1). In April and May, axial surface of oak leaves showed superhydrophobic properties achieving an average monthly tilted angle of the drop above $150^{\circ}$. This means that the drop adhered to the surface along a very small area and a slight movement could cause falling off the drops. In subsequent months, the tilted angles between the droplets and the surface decreased along with an increase in wettability. In September and October, stabilization within the average values of the contact angle of $80^{\circ}$ was observed. It was the upper limit of wettability referred to as a high wettability. In November, the contact angle was $40^{\circ}$ which was also classified as a high wettability.

In terms of the abaxial side of the leaf, higher values of the contact angle in comparison to axial side, were obtained in each month. Thus, every month the underside of the leaf is more difficult-to-wet (Figure 4). Therefore, in
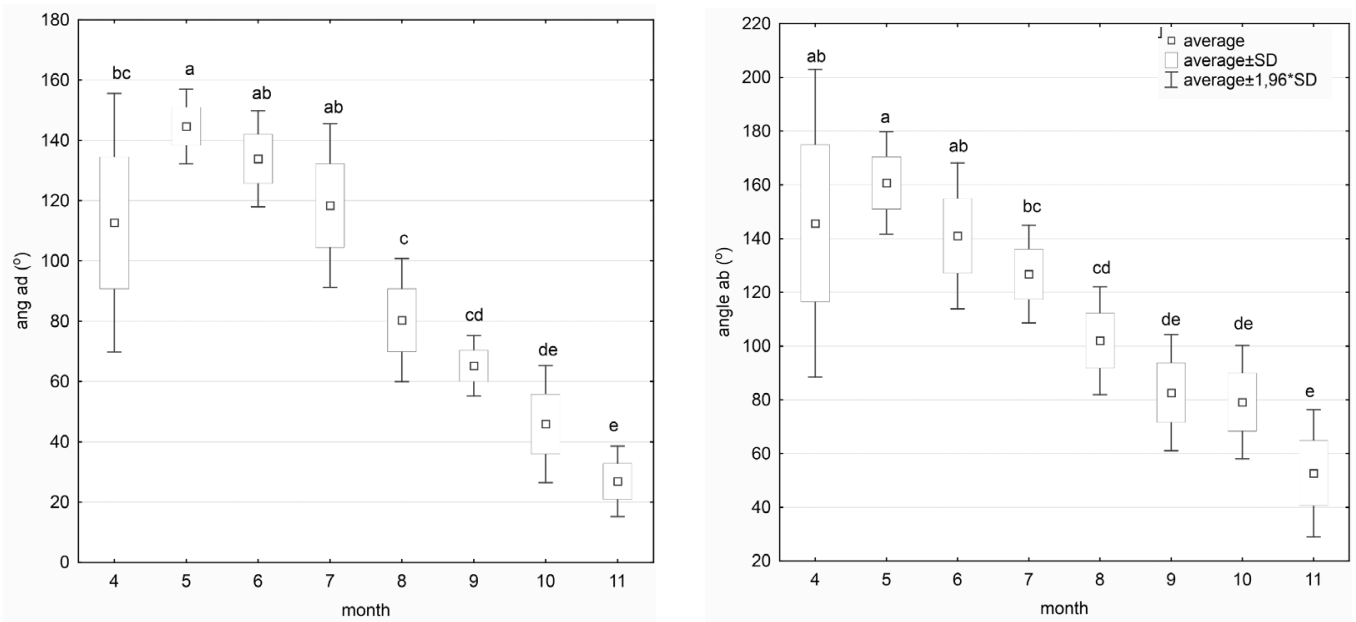

Figure 3 Seasonal changes in contact angle (left), respective adhesion (right), of drops on the adaxial side of leaf. Different lower case letters indicate significant differences. 
April it was about $110^{\circ}$, so the leaf was difficult-to-wet. In May and June, the average values of the contact angles were the highest, that is between 130 and $150^{\circ}$, and indicated that the leaves' surface could be considered a very difficult-to-wet. In May, June and July, changes in the tilted angles of drops were not statistically different between each other (Figure 4). Since August, increasing adhesion of the drops to leaves was observed. In November, contact angles were less than $40^{\circ}$ which is referred to as superhydrophilic leaves.

Contact angles between drops and leaves obviously correlated positively with the level of interception. The higher the wettability the greater the interception (Figure 5). From May to November, increase in the amount of retained water can be observed. Twigs were sprayed with a fixed dose of water equal to $5 \mathrm{~g}$. In May, June and July, we observed a mild increase in the value of interception established between $5.9 \%$ and $7 \%$ of the retained precipitation. In the following months, higher inter-

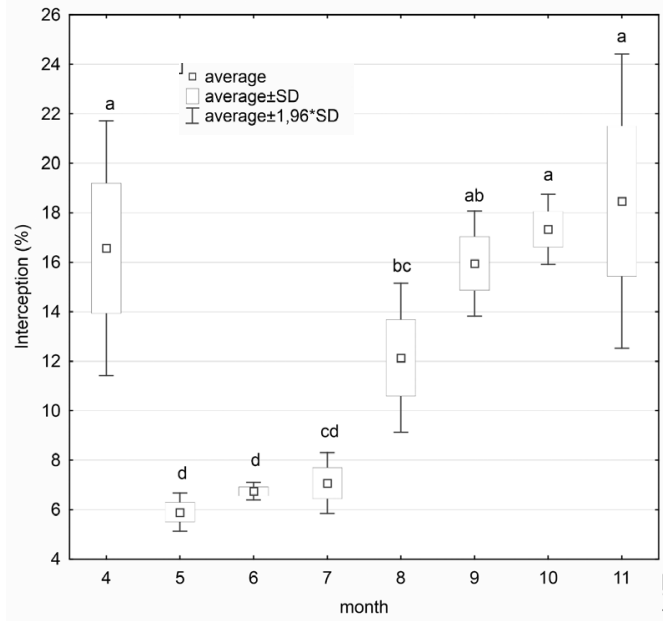

Figure 5 Seasonal changes of interception. Different lower case letters indicate significant differences. ception loss increased by about $18 \%$, which constitutes $0.9 \mathrm{~g}$ of the total simulated precipitation. The values of arrested precipitation in April are much higher than in the following spring and summer months. The amount of interception loss in April, with the value of $17 \%$ is close to that observed at the end of vegetation season reported in November, that is up to $18 \%$. There were no statistically significant differences between April and November, however the etiology of this situation is different for these 2 months.

Figure 6 shows the results of principal component analysis (PCA). Two principal components explain $77.1 \%$ of the total variance (principal component 1 and 2 explain 50.5\% and $26.6 \%$ of the variance, respectively). Principal component 1 is related to the content of alcohols, contact angles of drops to both, upper side and underside of a leaf, and interception. In addition, principal component 1 depends on fatty acids content. Considering principal component 2 , high values of loadings are at-

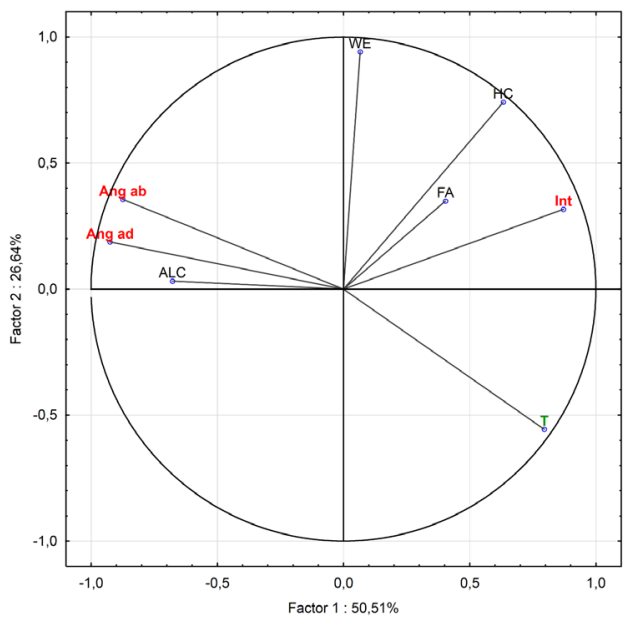

Figure 6 The projection of variables on a plane of the first and second factor;

Ang $\mathrm{ab}$ - the angle of droplets adhere to the upper side of the leaf, Ang ad - the angle of droplets adhere to the underside of the leaf, Int - interception, WE - wax esters, ALC - alcohols, HC - hydrocarbons, $\mathrm{T}$ - time (months), FA - fatty acids. 
tributed to the content of wax esters. The tilted angles between the leaves and drops are positively correlated with the amount of alcohol in the cuticle, and inversely correlated with the amount of triterpene esters. The level of interception is highly influenced by fatty acids, hydrocarbons and wax esters.

The GLM analysis result for the relationship of interception with the independent variables is presented in table 3 . The results shows the significance level and the interaction effect of variables. Using GLM analysis it was demonstrated that interception is affected by leaf age described as a month in which the samples were collected, and the contact angles of drops $(p=0.0000)$. The least important main effect in the prediction of interception using the GLM analysis was explained by the wax esters content $(p=0.0217)$.

\section{Discussion}

In this work, seasonal changes in the wettability of leaves surface and changes in the rainfall interception of common oak, were captured.

Images produced with an electron microscope constitute a complementary material for ecohydrological studies. In order to demonstrate the variability of the leaf surfaces at different stages of development, they are commonly used on a small-scale SEM (Tomaszewski 2004, Koch \& Barthlott 2009, Ensikat et al. 2010, Tranquada \& Erb 2014).

Table 3 Results of multivariable analysis of variance based on the general linear model (GLM)

\begin{tabular}{lcc}
\hline & \multicolumn{2}{c}{ Interception } \\
& $F$ & $p$-value \\
\hline Tx Ang ad & 6.81 & 0.0000 \\
Tx And ab & 2.22 & 0.0337 \\
WE & 5.34 & 0.0217 \\
\hline
\end{tabular}

Note. Abbreviation: T - month of sampling (April to November), Ang ab - the angle of droplets adhere to the upper side of the leaf, Ang ad - the angle of droplets adhere to the underside of the leaf, WE - wax esters. 70
Based on monthly measurements in labolatory condition, an increase in the amount of retained water from about $6 \%$ of the total simulated precipitation in May to more than 18\% of the retained precipitation in November, was reported. Similar relationships are observed during field measurements of seasonal changes of interception over the whole tree (Fathizadeh et al. 2013). The results obtained are consistent with changes in leaves wettability. Schreuder et al. (2001) found that increased leaf life span may reduce the hydrophobicity of leaves. Crocford \& Richardson (1990) and Sase et al. (2008) when performing experiments using both conifer and deciduous species found that older leaves were losing their hydrophobic properties.

Chemical changes occurring inside the leaf and the influence of atmospheric factors affect the texture of the leaf surface. It becomes more rugged and such surface retains more water. During the whole vegetation period, the underside of leaves shows higher values of contact angle than the axial side, therefore it is more resistant to water. On the upper side of the leaf, we observe a clear increase in the values of drops' adhesion in May which is reflected by lower values observed in April. This increase in hydrophobicity and the achievement of the highest values in May can be explained by the chemical structure of cuticle. The same relationship was reported for the level of interception assessed on the upper side of leaves. Epidermis of the upper side of the oak leaf is covered with thicker epithelium in comparison to the epidermis on the underside; on the upper side the crumbs is more prone to drying out. Stomata are located on the underside, which is less exposed to sunlight and lower amounts of dust is collected here, which could obstruct the stroma. These structural features of leaf affect the differences in the degree of wettability of the upper and lower sides of the leaves and also affect the level of interception. Fernandez et al. (2014) showed that regardless of leaf age, the upper side had a higher surface energy than the lower one, while this tendency in terms of 
polarity was opposite. This fact is explained by increased values of the contact angles between drops and leaves (i.e. less hydrophilicity) on the abaxial side of the leaves. In April, the forming leaves did not develop a layer which is responsible for self-cleaning associated with superhydrophobicity (Bhushan et al. 2010). Thus, much higher wettability and interception in the first month of analyzes is explained. Precise determination of seasonal changes can cause a significant difference in hydrologic balance. The amount of retained precipitation depends on the intensity and duration of precipitation (Klamerus-Iwan 2014b). It can be reported that low intensity precipitation lasting for a few minutes is almost entirely retained in the crown of trees. Presented studies demonstrate that change in adhesion and hydrophilicity of leaves must be taken into account when studying the interception. This fact has also an ecological justification. Much higher values of water adhesion in April, on a very young leaves can cause a common occurrence and development of oak powdery mildew (Erysiphe alphitoides) in early spring in juvenile or coppice shoots. For the proper development, oak powdery mildew requires moist environment.

The obtained results indicate how large the variability of drops' adhesion to a surface sprayed with water is, depending on changes occurring during the vegetation period. This is a topic of a growing interest for plant ecophysiology (Helliker \& Griffiths 2007, Limm \& Dawson 2010, Berry et al. 2014, Rosado \& Holder 2013, Berry et al. 2013, Helliker 2014) as they may play an important ecophysiological role.

Water capacity of trees' crowns and the amount of water transferred into the under-crown zone is often a necessary condition for the restoration of desert ecosystems for xerophytic shrubs and in semiarid tree plantations (Sadeghi et al. 2014). In dry climate, adaptation of trees not to retain water on the leaves can be observed so that more water can enter the soil (Martin \& von Willert 2000,
Holder 2012).

Nevertheless, the mechanisms of foliar uptake of water and solutes by plant surfaces are still not fully understood (Fernández \& Eichert 2009, Burkhardt \& Hünsche 2013).

\section{Acknowledgments}

This Research was finance by the Ministry of Science and Higher Education of the Republic of Poland. The images using Scanning Electron Microscope (SEM) were taken at the Institute of Cell Imaging at the Jagiellonian University.

\section{References}

Adamec L., 2013. Foliar mineral nutrient uptake in carnivorous plants: what do we know and what should we know? Frontiers in Plant Science 4: 10. DOI: $10.3389 /$ fpls.2013.00010

Aryal B., Neuner G., 2010. Leaf wettability decreases along an extreme altitudinal gradient. Oecologia 162: 1-9. DOI: 10.1007/s00442-0091437-3

Aussenag G., 2000. Interaction between forest stands and microclimate: Ecophysiological aspects and consequences for silviculture. Annals of Forest Science 57: 287-301. DOI: 10.1051/ forest:2000119

Barthlott W., Neinhuis C., 1997. Purity of the sacred lotus leaf, of escape from contamination in biological surfaces. Planta 202(1): 1-8. DOI: $10.1007 / \mathrm{s} 004250050096$

Berry Z.C., Hughes N.M., Smith W.K., 2013. Cloud immersion: an important water source for spruce and fir saplings in the southern Appalachian Mountains. Oecologia 173(3): 637-648. DOI: 10.1007/s00442-013-2653-4

Berry Z.C., Hughes N.M., Smith W.K., 2014. Cloud immersion: an important water source for spruce and fir saplings in the southern Appalachian Mountains. Oecologia 174 (2): 319-326. DOI: 10.1007/s00442-013-2770-0

Bhushan B., Jung Y.C., 2006. Micro- and nanoscale characterization of hydrophobic and hydrophilic leaf surfaces. Nanotechnology 17(11): 27582772. DOI: $10.1088 / 0957-4484 / 17 / 11 / 008$ 
Burkhardt J., Hunsche M., 2013. Breath figures on leaf surfaces - formation and effects of microscopic leaf wetness. Frontiers in Plant Science 4: 422. DOI: $10.3389 /$ fpls.2013.00422

Calder I.R., 1999. Dependence of rainfall interception on drop size - a reply to the comment by Uijlenhoet and Stricker. Journal of Hydrology 217: 164-165. DOI: 10.1016/S00221694(99)00003-7

Chang M., 2006. Forest hydrology: An introduction to water and forests. $2^{\text {nd }}$ ed. Boca Raton, FL, USA: Taylor and Francis.

Chen S., Chen C., Zou C.B., Stebler E., Zhang S., Hou L., Wang D., 2013. Application of Gash analytical model and parameterized Fan model to estimate canopy interception of a Chinese red pine forest. Journal of Forest Research 18: 335-344. DOI: $10.1007 / \mathrm{s} 10310-012-0364-\mathrm{z}$

Crockford R.H., Richardson D.P., 1990. Partitioning of rainfall in a eucalypt forest and pine plantation in southeastern Australia: I. throughfall measurement in a eucalypt forest: effect of method and species composition. Hydrological Processes 4: 131-144. DOI: 10.1002/hyp.3360040204

Ensikat H.J., Ditsche-Kuru P., Barthlott W., 2010. Scanning electron microscopy of plant surfaces: simple but sophisticated methods for preparation and examination. In Méndez-Vilas, A., Diaz, J. (Eds.), Microscopy: science, technology, applications and Education. FORMATEX Microscopy series No. 4(1):248-255.

Extrand C.W., 2005. Modeling of ultralyophobicity: suspension of liquid drops by a single asperity. Langmuir 21:10370-10374.

Fernández V., Eichert T., 2009. Uptake of hydrophilic solutes through plant leaves current state of knowledge and perspectives of foliar fertilization. Critical Reviews in Plant Sciences 28: 3668. DOI: $10.1080 / 07352680902743069$

Fernández V., Guzmán P., Peirce C.A.E., McBeath T.M., Khayet M., McLaughlin M.J., 2014. Effect of wheat phosphorus status on leaf surface properties and permeability to foliar applied phosphorus. Plant and Soil 384(1): 7-20. DOI: 10.1007/ s11104-014-2052-6

Fathizadeh O., Attarod P., Pypker T.G., Darvishsefat A.A., Zahedi Amiri G., 2013. Seasonal variability of rainfall interception and canopy storage capacity measured under individual oak (Quercus brantii) trees in Western Iran. Journal of Agricultural Science and Technology 15: 175-188.

Gash J.H.C., Loyd C.R., Lachaud G., 1995. Estimating sparse forest rainfall interception with an analytical model. Journal of Hydrology 170:7986. DOI: 10.1016/0022-1694(95)02697-N

Gülz, P.G., Müller E., 1992. Seasonal variation in the composition of epicuticular waxes of Quercus robur leaves. Verlag der Zeitschrift für Naturforschung 47: 800-806.

Helliker B.R., Griffiths H., 2007. Towards a plantbased proxy for the isotope ratio of atmospheric water vapor. Global Change Biology 13:723-733. DOI: $10.1111 / \mathrm{j} .1365-2486.2007 .01325 . x$

Helliker B.R., 2014. Reconstructing the $\delta 180$ of atmospheric water vapour via the CAM epiphyte Tillandsia usneoides: seasonal controls on $\delta 18 \mathrm{O}$ in the field and large-scale reconstruction of 818Oa. Plant, Cell \& Environment 37: 541-556. DOI: 10.1111 pce. 12167

Holder C.D., 2007. Leaf water repellency as an adaptation to tropical montane cloud forest environments. Biotropica 39: 767-770. DOI: 10.1111/j.1744-7429.2007.00303.x

Holder C.D., 2012. The relationship between leaf hydrophobicity, water droplet retention, and leaf angle of common species in a semi-arid region of the western United States. Agricultural and Forest Meteorology 152: 11-16. DOI: 10.1016/j. agrformet.2011.08.005

Holder C.D., 2013. Effects of leaf hydrophobicity and water droplet retention on canopy storage capacity. Ecohydrology 6: 483-490. DOI: 10.1002/ eco. 1278

Johnstone J.A., Dawson T.E., 2010. Climatic context and ecological implications of summer fog decline in the coast redwood region. Proceedings of the National Academy of Sciences 107: 45334538. DOI: 10.1073/pnas.0915062107

Keim R.F., Skaugset A.E., Link T.E., Iroumé A., 2004. A stochastic model of throughfall for extreme events. Hydrology and Earth System Sciences 8: 23-34. DOI: 10.5194/hess-8-23-2004

Klaassen W., Lankreijer H.J.M., Veen A.W.L., 1996. Rainfall interception near a forest edge. Journal of Hydrology 185: 349-361. DOI: 10.1016/00221694(95)03011-5

Klamerus-Iwan A., 2014a. Potential interception in laboratory condition under simulated rain with low intensity. Sylwan 158: 292-297.

Klamerus-Iwan A., 2014b. Potential interception of sprayed tree in relations to tree species and changes occurring during single rainfall. Sylwan 158: 867-874.

Koch K., Barthlott W. 2009. Superhydrophobic and super- hydrophilic plant surfaces: an inspiration for biomimetic materials. Philosophical Trans- 
actions of the Royal Society A: Mathematical, Physical and Engineering Sciences 367: 14871509.

Kozlowski T., Pallardy S.G., 1979. Physiology of woody plants. Academic Press.

Li W., Amirfazli A., 2008. Hierarchical structures for natural superhydrophobic surfaces. Soft Matter 4: 462-466. DOI: 10.1039/B715731B

Limm E.B., Simonin K.S., Bothman A.G., Dawson T.E., 2009. Foliar water uptake: A common water acquisition strategy for plants of the redwood forest. Oecologia 161: 449-459. DOI: 10.1007/ s00442-009-1400-3

Limm E.B., Dawson T.E., 2010. Polystichum munitum (Dryopteridaceae) varies geographically in its capacity to absorb fog water by foliar uptake within the redwood forest ecosystem. American Journal of Botany 97: 1121-1128. DOI: 10.3732/ ajb. 1000081

Liu S., 1997. A new model for the prediction of rainfall interception in forest canopies. Ecological Modeling 99: 151-159. DOI: 10.1016/S0304-3800(97)01948-0

Martin C.E., Von Willert D.J., 2000. Leaf epidermal hydathodes and the ecophysiological consequences of foliar water uptake in species of Crassula from the Namib Desert in southern Africa. Plant Biology 2: 229-242. DOI: 10.1055/s-20009163

Nanko K., Hotta N., Suzuki M., 2006. Evaluating the influence of canopy species and meteorological factors on throughfall drop size distribution. Journal of Hydrology 329: 422-431. DOI: 10.1016/j.jhydrol.2006.02.036

Nanko K., Watanabe A., Hotta N., Suzuki M., 2013. Linkage between canopy water storage and drop size distributions of leaf drips. Agricultural and Forest Meteorology 169: 74-84. DOI: 10.1016/j. agrformet.2012.09.018

Neinhuis C., Barthlott W., 1997. Characterization and distribution of water-repellent, self-cleaning plant surfaces. Annals of Botany 79: 667-677. DOI: 10.1006/anbo.1997.0400

Otten A., Herminghaus S., 2004. How plants keep dry: a physicist's point of view. Langmuir 20: 2405-2408. DOI: 10.1021/la034961d

Owsiak K., Klamerus-Iwan A., Gołąb J., 2013. Effect of current state of the sprinkled surface on rain water coherence - laboratory research on interception by trees. Sylwan 157: 922-928.

Pike R.G., Scherer R., 2003. Overview of the potential effects of forest management on low flows in snowmelt-dominated hydrologic regimes. BC
Journal of Ecosystems and Management 3(1): 44-60.

Pretzsch H., Bielak K., Block J., Bruchwald A., Dieler J., Ehrhart H-P., Kohnle U., Nagel. J, Spellmann H., Zasada M., Zingg A., 2013. Productivity of mixed versus pure stands of oak (Quercus petraea (Matt.) Liebl. and Quercus robur L.) and European beech (Fagus sylvatica L.) along an ecological gradient. European Journal of Forest Research 132: 263-280. DOI: 10.1007/s10342012-0673-y

Rosado B.H.P., Holder C.D., 2013. The significance of leaf water repellency in ecohydrological research: a review. Ecohydrology 6:150-161. DOI: 10.1002/eco. 1340

Sadeghi S.M.M., Attarod P., Pypker T.G., Dunkerley D., 2014. Is canopy interception increased in semiarid tree plantations? Evidence from a field investigation in Tehran, Iran. Turkish Journal of Agriculture and Forestry 38:792-806. DOI: 10.3906/tar-1312-53

Sase H., Takahashi A., Sato M., Kobayashi H., Nakata M., Totsuka T., 2008. Seasonal variation in the atmospheric deposition of inorganic constituents and canopy interactions in a Japanese cedar forest. Environmental Pollution 152 (1):1-10. DOI: 10.1016/j.envpol.2007.06.023

Schreuder M., Van Hove L.W.A., Brewer C.A., 2001. Ozone exposure affects leaf wettability and tree water balance. The New Phytologist 152(3): 44354. DOI: 10.1046/j.0028-646X.2001.00272.x

Stosch A.K., Solga A., Steiner U., Oerke C., Barthlott W., Cerman Z., 2007. Efficiency of self-cleaning properties in wheat (Triticum aestivum L.). Journal of Applied Botany and Food Quality 81:49-55.

Tomaszewski D., 2004. The wax layer and its morphological variability in four $\mathrm{Eu}-$ ropean Salix species. Flora 199:320-326. DOI: $10.1078 / 0367-2530-00159$

Tranquada G.C., Erb U., 2014. Morphological development and environmental degradation of superhydrophobic aspen and black locust leaf surfaces. Ecohydrology 7:1421-1436. DOI: 10.1002/eco. 1468

Woś A ., 1996. Meteorologia dla geografów [Meteorology for the geographer]. Wydawnictwo Naukowe PWN, Warszawa.

Xiao Q., McPherson E., 2016. Surface water storage capacity of twenty tree species in Davis, California. Journal of Environmental Quality. 45, 188-198. DOI: $10.2134 /$ jeq2015.02.0092 